\title{
The Construction of Hierarchical Teaching and Training Model in College Basketball Education
}

\author{
Xiaoqian Yue \\ Chengdu Medical College, Chengdu, Sichuan Province, China
}

Keywords: college basketball education; hierarchical teaching; training; model; construction.

\begin{abstract}
In view of students' individual differences, the hierarchical teaching and training model should be constructed in the process of college basketball education. Teaching objectives and programs should be planned in advance and with purpose; the work of basketball teaching and training should be actively carried out in campus. This paper objectively and comprehensively explains the theoretical connotation, principles and contents of the hierarchical teaching and training model, analyzes the necessity of construction this model in college basketball education, and puts forward specific implementation methods.
\end{abstract}

\section{Introduction}

In China, basketball course is a basic part of college physical education. It plays an important role in strengthening college students' physiques and inspiring their sports enthusiasm. In college basketball lessons, teachers need to enrich teaching methods and organize teaching contents more scientifically; they also need to design and construct the hierarchical teaching and training model according to students' individual differences on cognitive levels, exercise capacities and the abilities of learning new things.

\section{The Theoretical Connotation of Hierarchical Teaching and Training in College Basketball Education}

Educational psychologists believe that students' learning outcomes are related to internal factors and the external environment. [1] If we can fully mobilize the internal factors of college students and skillfully connect internal factors with the external environment, we can stimulate their study enthusiasm, mobilize their study initiatives, and give full play to their individual potentials to achieve better study results. In colleges and universities, the traditional physical education mode tends to provide a unified learning environment for students. But the existing external learning environment is not suitable for individual needs of students since it fails to fully consider the individual differences. The theory of hierarchical teaching and training in college basketball education insists on the dominant position of students. Teachers are required to understand and grasp students' individual differences comprehensively through pre-class tests and questionnaires, and then rationally classify students into different levels in order to set teaching objectives and contents in a planned, purposeful and targeted way. Adopting hierarchical teaching methods can motivate students' internal factors and creates a good study environment for them.

\section{The Principles and Contents of Hierarchical Teaching and Training in College Basketball Education}

\subsection{The hierarchy of students.}

To promote the healthy development of basketball education in colleges, the key is to implement hierarchical teaching methods and take students' different learning requirements into consideration. [2] Students should take the leading role in basketball lessons; teaching objectives and learning tasks 
should be formulated scientifically and purposefully according to students' differences in gender, personalities, physical fitness, basic basketball skills, hobbies, sport habits and emotional attitudes. Basketball teachers in colleges and universities must adhere to the student-oriented principle, and fully understand students' individual differences and personal demands. In the training process, the hierarchical teaching and training mode should be adopted according to students' characteristics. Students need to be divided into different groups in order to formulate targeted training plans and programs. Through the implementation of hierarchical teaching and training mode, basketball lessons can be equipped with more substantial teaching contents more clear and accurate teaching goals, more appropriate teaching methods, as well as more scientific and effective teaching evaluation methods. The hierarchical mode can meet students' diversified equipments on basketball learning and help school authorities to carry out targeted basketball teaching and training activities, so as to train students' basketball skills and improve their athletic abilities.

\subsection{The hierarchy of teaching objectives.}

In colleges and universities, the traditional basketball teaching mode requires teachers to carry out teaching and training activities according to the unified teaching objectives issued by the Ministry of Education. Teachers only need to carry out activities according to the established syllabus; teaching settings are lack pertinence and effectiveness. In colleges, the teaching objectives of basketball course should be determined according to the different levels of students. Analyze from the macro level, the teaching objectives are set for all students; but from the micro point of view, teaching goals should take college students' personal characteristics into account. College students' different interests, physical fitness, sports abilities and sports knowledge should be taken into account. These characteristics and differences should be fully considered with the characteristics of basketball lessons and the framework of college education; only in this way, can we formulate teaching objectives which are suitable for students with different heights, physical fitness, basketball skills, offensive capacities as well as defensive abilities. Hierarchical teaching objectives help teachers to carry out different training models, and further improve basketball lessons in colleges and universities. At the same time, in the process of implementing teaching objectives, school authorities should adjust these goals at any time according to the actual situation, and constantly enrich and improve the training contents. The school also needs to provide students with a real combat environment so as to to train their team spirit and improve their basketball skills.

\subsection{The hierarchy of teaching guidance system.}

When choosing the guidance system, college basketball teachers should adhere to the concept of teaching students in accordance with their aptitude, and adopt appropriate education and guidance systems according to the characteristics of students at different levels. In terms of educational level, since the interests, basketball skills and learning abilities of college students are different, the teacher should formulate different teaching plans and design diversified teaching contents according to the individual differences of students. Students who are not good at basketball should focus on basic training. The teacher should guide them to grasp basic basketball theories, rather than difficult skills and movements. Students with general basketball skills should lay emphasis on teamwork as well as basketball tactics and strategies on the basis of fundamental basketball theory and skills. The teacher should guide them to carry out independent learning and training activities. Outstanding students should attach importance to team cooperation as well as strategic and tactical capabilities. They should challenge themselves in mastering difficult basketball skills and actions on the basis of basic training. Through stratified teaching methods, colleges and universities can guide students to actively participate in basketball courses and training activities, and stimulate their enthusiasm as well as interests in basketball learning.

\subsection{The hierarchy of evaluation system.}

In colleges and universities, PE teachers should develop diversified teaching contents and evaluation systems for basketball course based on characteristics of students at different levels. When design the evaluation system, teachers should fully consider the development of basketball course 
and the characteristics of college students, so as to improve the evaluation mechanism and formulate comprehensive evaluation methods. Factors like students' attendance rate, theoretical knowledge and basketball skills, as well as the situation of team cooperation in competitions and trainings should all be included in the evaluation system. Rational scores should be employed to define evaluation contents, indexes and standards in order to make the evaluation system more pertinent, hierarchical and scientific. At the same time, colleges and universities should continue to enrich the contents and forms of evaluation system. Through the development of targeted evaluation activities like students' self-evaluation and mutual evaluation and teachers' quantitative evaluation, a system which can investigate college students' comprehensive qualities and emotional attitude towards basketball can be established; a diversified, multi-level and all-round evaluation system can be built.

\section{The Necessity of Construction Hierarchical Teaching and Training Model in College Basketball Education}

The hierarchical teaching and training adheres to the student-oriented principle, adapts to the general direction of China's education reform, and conforms to the law of college students' physical education. It is necessary to implement this mode so as to deepen the reform in college basketball education, strengthen the construction of characteristic basketball curriculum, and optimize the setting of basketball courses. Implementing the hierarchical teaching and training mode is the necessary requirement of perfecting the teaching contents and training methods of college education, and the requirement of improving college students' sports abilities and learning outcomes. Hierarchical teaching and training mode insists on the principle of teaching students in accordance with their aptitude, and can mobilize students' learning initiatives. It can help college students to improve their basketball skills, and cultivate their sense of cooperation and team spirit. The hierarchical teaching and training mode in basketball lessons can also guide college students to set up correct values, cultivate their spirit of initiative and cooperate, and create a good cultural environment on campus.

\section{Methods of Implementing Hierarchical Teaching and Training in College Basketball Education}

\subsection{Carrying out hierarchical teaching and training activities in basketball lessons according to students' personality characteristics.}

To implement hierarchical teaching and training in basketball lessons, college teachers should fully consider the personality characteristics of college students and carry out basketball teaching and training activities for students at different levels. Before the official start of course, teachers should organize pre-class tests to comprehensively grasp the situation of students' learning levels and basic abilities. Pre-class assessment can be carried out through questionnaires, field investigation and competitions. The results of assessment can help teachers to grasp the basic situation of college students, and carry out stratified teaching activities more pertinently and scientifically. Teachers need to make comprehensive consideration and evaluation on students' interests, physical conditions, fitness, sports abilities and knowledge absorbing abilities, in order to carry out specific and practical teaching and training activities at class. For students' weak points, teachers can carry out intensive training and special teaching, which are conducive to the construction of hierarchical teaching and training model in basketball lessons of colleges and universities.

\subsection{Scientifically setting up teaching objectives for students with different levels.}

In order to implement hierarchical teaching and training in basketball course, college teachers should scientifically design teaching objectives and teaching contents according to the personality characteristics of college students and the training plans for students at different levels, so as to make the basketball courses more targeted and purposeful. When setting teaching objectives, teachers should not only classify students according to their individual differences, but also comprehensively 
grasp the overall situation of students' characteristics and physical agility. They need to take into account of students' individual differences on personalities, physical conditions, sports abilities and emotional attitudes. In order to further improve the quality of basketball education in colleges and universities, teachers should learn teaching laws in basketball education, formulate teaching objectives in accordance with students' characteristics, and actively carry out different training projects. At the same time, in the process of implementing basketball teaching objectives, different teaching objectives and teaching plans should be set according to the different levels and needs of college students. Teaching objectives and syllabus should be adjusted at any time according to actual teaching situations, so as to actively improve the content system and promote model construction. Teachers should strengthen the teaching and training of specialized skills so as to create a scientific basketball learning and training environment for college students.

\subsection{Paying attention to design and guidance in basketball teaching and fully considering the different levels of students.}

Under the long-term influence of the traditional education mode, in colleges and universities, the commonly used organizational form in basketball course is still the uniform and standardized education mode. Teachers explain in a unified way; students practice according to unified rules; fixed standards are the main evaluation method: these measures sharpen contradictions in college basketball education.[3] In the hierarchical teaching and training model, the school should always adhere to the student-oriented concept and teach students in accordance with their aptitude; teachers should adopt education and guidance modes in accordance with the characteristics of college students at different levels, so as to better promote the development of basketball education. On the basis of college students' understanding on basketball theories and their basic capacities, college students should be divided into three groups. Students who are not good at basketball should focus on basic training. The teacher should guide them to grasp basic basketball theories, rather than difficult skills or actions, in order to consolidation their foundation. Students with general basketball skills should lay emphasis on basketball tactics and strategies on the basis of fundamental basketball theory and skills. The teacher should guide them to carry out independent learning and training. Outstanding college students should learn basketball concepts as well as game strategies and tactics from advanced countries, and imitate the actions of NBA and CBA stars. They should challenge themselves in mastering difficult basketball skills and actions and enhancing team cooperation. In the process of basketball education, colleges and universities need to adopt hierarchical teaching methods, focus on teaching design, and guide students in learning and training methods so as to arouse their enthusiasm and interests in basketball learning.

\subsection{Establishing diversified evaluation system according to students' different abilities of learning new things.}

The hierarchical teaching and training model in college basketball education requires a diversified teaching evaluation system and various teaching contents which are constructed according to students' different abilities of learning new things. A diversified evaluation system on basketball education should be actively constructed in colleges. Teachers can establish the evaluation system through four indicators: theoretical knowledge, basketball skills, learning attitude and team spirit. [4] Students' theoretical knowledge on basketball can be tested through closed-book examination; their basketball skills should be inspected in practice. According to the individual differences of college students, the emphasis should be put on testing their dribbling abilities, basketball skills and practical abilities. Their motivation and attitudes toward basketball learning should also be investigated; good motivation and correct attitudes are conducive to the learning and consolidation of knowledge, and can help students to improve their basketball skills. Cooperation consciousness is the concentrated embodiment of team spirit. Good team cooperation is conducive to the cultivation of solidarity spirit and coordination skills, which are helpful to improve the moral sentiments of college students. At the same time, colleges and universities should continue to improve the evaluation mechanism. A sound evaluation system should include factors like students' attendance, basic theoretical knowledge and skills, as well as their performances in training and competitions. A diversified basketball evaluation 
system can reflect students' learning situation more scientifically and objectively.

To sum up, implementing hierarchical teaching and training in college basketball course can improve education concepts and teaching results, strengthen new curriculum reform and improve students' learning interests. Institutions of higher learning should adhere to the principle of people-oriented and teaching students in accordance with their aptitude, strengthen the understanding of hierarchical teaching and training, reform education methods, improve education levels and actively explore methods of implementing hierarchical teaching and training in basketball lessons.

\section{References}

[1] B. Yu, Research on the construction of hierarchical teaching and training mode in basketball lessons of college, J. Time Education. 09 (2018).

[2] J. Kan, Research on the construction of hierarchical teaching and training mode in basketball lessons of colleges and universities, J. Sports. 06 (2016).

[3] Y.F. Ding, The application of stratified teaching method in basketball lessons of college, J. Contemporary Sports Technology. 06 (2016).

[4] S.X. Shi, Construction of hierarchical teaching and training mode in basketball lessons of colleges and universities, J. Contemporary Sports Technology. 03 (2013). 